\title{
Unexpected Complication of a Multinodular Goitre
}

Paulien MM van Hauten ${ }^{1}$,Gysele S Bleumink², Marcel MC Hovens ${ }^{3}$, Ton AJM Rijnders ${ }^{4}$, Ruth Ekhart ${ }^{2}$

${ }^{1}$ Department of Internal Medicine, Rijnstate Hospital Arnhem, Arnhem, The Netherlands

2Department of Endocrinology, Rijnstate Hospital Arnhem, Arnhem, The Netherlands

${ }^{3}$ Department of Vascular Medicine, Rijnstate Hospital Arnhem, Arnhem, The Netherlands

${ }^{4}$ Department of Nuclear Medicine, Rijnstate Hospital Arnhem, Arnhem, The Netherlands

Received: 18/12/2015

Accepted: $18 / 12 / 2015$

Published: 22/01/2016

How to cite this article: van Hauten PMM, Bleumink GS, Hovens MCC, Rijnders TAJM, Ekhart R. Unexpected complication of a multinodular goitre. EJCRIM 2016;3:doi:10.12890/2016_000363

Conflicts of Interests: The authors declare that there are no competing interests.

This article is licensed under a Commons Attribution Non-Commercial 4.0 License

\section{ABSTRACT}

Multinodular goitre is the most common thyroid gland disorder. It can cause hyperthyroidism and mechanical complaints such as tracheal compression or dysphagia. We report a unique case of a patient with a toxic multinodular goitre presenting with a deep venous thrombosis of the left arm due to direct local compression of blood flow.

\section{LEARNING POINTS}

- Multinodular goitre can cause deep venous thrombosis of the upper extremity due to local compression of blood flow.

- Hyperthyroidism causes a hypercoagulable and hypofibrinolytic state which, if left untreated, is a risk factor for venous thrombosis.

- A diagnostic algorithm combining the Constans clinical score, D-dimer testing and, when indicated, ultrasonography is a safely and effectively approach for investigating suspected deep venous thrombosis of the upper extremity.

\section{KEYWORDS}

Hyperthyroidism, multinodular goitre, venous thromboembolism.

\section{INTRODUCTION}

Multinodular goitre (MNG) is a thyroid gland disorder common in general practice and with a prevalence of 0.7 per 1,000 patients. It tends to grow slowly but steadily. Symptoms are related to the growth and hormonal activity of the tissue. Compression of the trachea, the oesophagus and neural structures causes dyspnoea, orthopnoea, asphyxia, dysphagia, dysphonia and Horner's syndrome. Symptoms of hyperthyroidism include anxiety, weight loss, palpitations, heat sensitivity and tremors. The prevalence of malignancy in MNG is approximately 3-5\%, which is lower than that in single nodules. Here we describe an uncommon and relatively unknown but potentially life-threatening complication of MNG.

\section{CASE REPORT}

A 89-year-old woman without a relevant medical history apart from a recently diagnosed toxic MNG was admitted to the hospital with nausea and diarrhoea. Treatment with strumazol had already reduced the thyroxine level from $94 \mathrm{pmol} / \mathrm{l}$ to $48 \mathrm{pmol} / \mathrm{l}$ in $1 \mathrm{week}$. The working diagnosis was gastrointestinal complaints due to hyperthyroidism caused by MNG. At admittance, physical examination revealed a painless swelling of the left arm with pitting oedema. Duplex ultrasound showed thrombosis in the left jugular vein and subclavian vein with distal 
collateralization. Computed tomography (CT) showed a large retrosternal mass originating from the left thyroid lobe with extension into the mediastinum upon the aortic arch, causing displacement and stenosis of the trachea and located adjacent to the brachiocephalic vein causing compression of blood flow (Fig. 1).

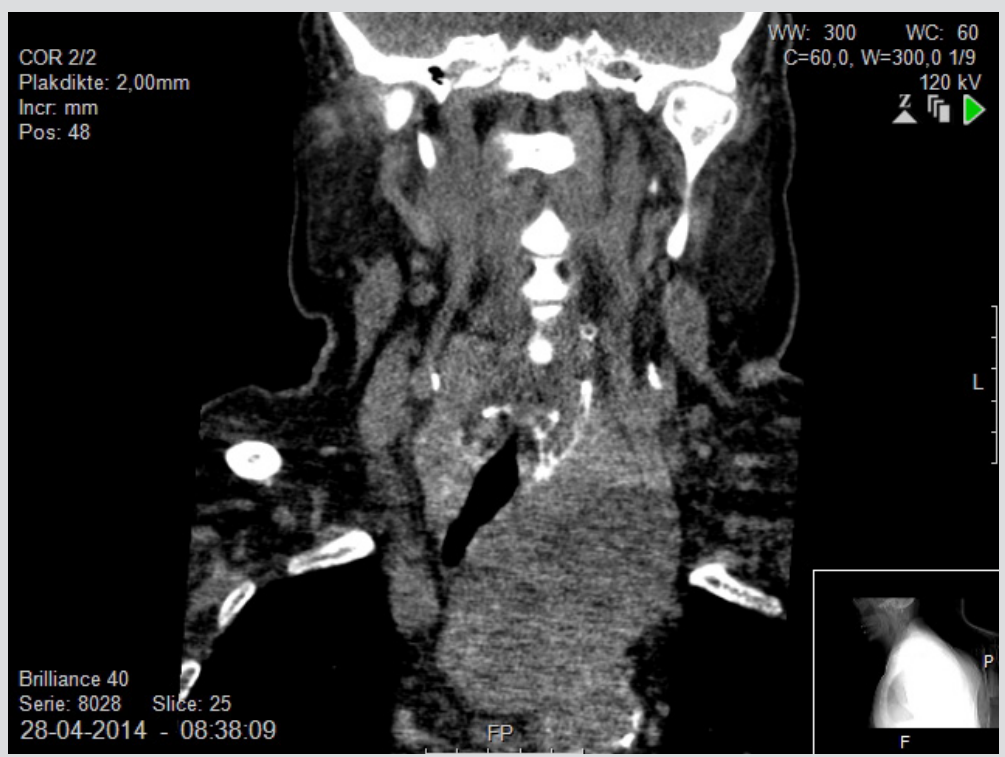

Figure 1. CT scan, coronal plane, showing a large goitre with displacement of the trachea

The patient was started on anticoagulation therapy. Thorough anamnesis, physical examination, chest x-ray and abdominal ultrasound revealed no signs of associated malignancy.

\section{DISCUSSION}

Toxic MNG is a common benign cause of hyperthyroidism. This case shows that toxic MNG can be associated with venous thrombosis of the upper extremity due to mechanical alterations in blood flow and chemical hypercoagulability provoked by hyperthyroidism.

Venous thrombosis

The incidence of deep venous thrombosis of the upper extremity (UEDVT) and the internal jugular vein has been increasing since the common use of central venous catheters was introduced. The underlying pathophysiological processes of Virchow's triad result in a broad spectrum of predisposing factors (Table 1) $)^{[1]}$.

Patients with a thrombosis of the upper extremity present with a tired, heavy feeling in their arm accompanied by pain. Physical examination shows swelling of the arm with a restricted range of motion and dilated cutaneous veins. The differential diagnosis includes lymphoedema or an inflammation of the skin. A diagnostic algorithm combining the Constans clinical score, D-dimer testing and, when indicated, ultrasonography is a safe and effective method to exclude thrombosis in patients with suspected UEDVT ${ }^{[2]}$.

Early severe complications of UEDVT include pulmonary embolism (2.7-36\%) and intracranial propagation of the thrombus (17.5\%). In the long term, patients may experience arm swelling, pain and discomfort due to valvular damage and residual mural thrombus leading to post-thrombotic syndrome. Anticoagulation therapy is the first-choice treatment in the early phase and should be continued for at least 3 months, depending on predisposing factors.

This case shows that the slow and steady growth of a substernal goitre can cause UEDVT. This condition has been described only rarely in the literature ${ }^{[1,3,4]}$. UEDVT can be the presenting symptom of a previously silent substernal goitre ${ }^{[3]}$. The slow growth rate of a substernal goitre usually permits the development of a collateral circulation.

Hyperthyroidism

As described above, venous thromboembolism (VTE) has a multifactorial aetiology due to numerous genetic and acquired risk factors. Hyperthyroidism is also pathophysiologically and clinically associated with VTE. Patients with hyperthyroidism show elevated levels of 


\begin{tabular}{|c|l|}
\hline Circulatory stasis & Hypercoagulable state \\
\hline Immobility or paralysis (plaster cast) & Active malignancy \\
\hline Lymphoma & Chemotherapy \\
\hline Anatomic abnormalities & Pregnancy and peri-partum period \\
\hline Unusual exercise & Oestrogen therapy \\
\hline Endothelial injury & Trauma \\
\hline Unusual exercise & Inflammatory bowel disease \\
\hline Trauma or surgery & Nephrotic syndrome \\
\hline Central venous catheter & Sepsis \\
\hline Radiotherapy & Thrombophilia \\
\hline Atherosclerosis & Hyperthyroidism \\
\hline
\end{tabular}

Table 1. Risk factors for deep venous thrombosis of the arm

VWF and enhanced platelet function, elevated levels of coagulation factors VIII and IX, fibrinogen and plasminogen activator inhibitor-1 (PAI-1) and decreased levels of plasminogen activator (t-PA). This results in a hypercoagulable and hypofibrinolytic state which returns to normal after successful treatment of the hyperthyroidism. A retrospective multicentre cohort study of 587 patients with a first episode of hyperthyroidism showed a higher incidence of VTE compared to the general population (8.7 versus $0.7-1.8$ per 1,000 person-years), with the majority of thrombotic events occurring before diagnosis and before anti-thyroid pharmacotherapy ${ }^{[5]}$.

\section{CONCLUSION}

In conclusion, this case report describes a thrombosis in the left jugular vein and subclavian vein caused by a toxic MNG compressing the innominate vein. Circulatory stasis and chemical hypercoagulability both contributed to the pathophysiological process. UEDVT is associated with benign substernal goitre and hyperthyroidism and can be the first presenting symptom.

\section{REFERENCES}

1. Lønnebakken MT, Pedersen OM, Andersen KS, Verhaug JE. Incidental detection of internal jugular vein thrombosis secondary to undiagnosed benign substernal goiter. Case Rep Med 2010;645193.

2. Kleinjan A, Di Nisio M, Beyer-Westendorf J, Camporese G, Cosmi B, Ghirarduzzi A, et al. Safety and feasibility of a diagnostic algorithm combining clinical probability, D-dimer testing, and ultrasonography for suspected upper extremity deep venous thrombosis. Ann Intern Med 2014;160:451-457.

3. Hauer Santos G, Ghalili K. Axillosubclavian vein thrombosis produced by retrosternal thyroid. Chest 1990;98:1281-1283.

4. Khan AM, Khan S. Retrosternal thyroid mass resulting in axillosubclavian vein thrombosis. BMJ Case Rep 2014 Feb 5;2014. pii: bcr2013202450. doi: 10.1136/bcr-2013202450 (accessed 4 Jan 2016).

5. Kootte RS, Stuijver DJF, Dekkers OM, van Zaane B, Fliers E, Cannegieter SC, et al. The incidence of venous thromboembolism in patients with overt hyperthyroidism. Thromb Haemost 2012;107:417-422. 